\title{
Polymorphism of the salt sensitivity gene angiotensinogen and gastric cancer risk
}

\author{
TOMOYUKI SHIBATA ${ }^{1}$, TOMOMITSU TAHARA ${ }^{1}$, TOMIYASU ARISAWA ${ }^{2}$ and ICHIRO HIRATA ${ }^{1}$ \\ ${ }^{1}$ Department of Gastroenterology, Fujita Health University School of Medicine, Toyoake, Aichi 470-1192; \\ ${ }^{2}$ Department of Gastroenterology, Kanazawa Medical University, Kahoku-gun 920-0293, Japan
}

Received March 30, 2011; Accepted May 9, 2011

DOI: $10.3892 / \mathrm{mmr} .2011 .495$

\begin{abstract}
A high-salt diet is a risk factor for gastric cancers other than those caused by Helicobacter pylori. The angiotensinogen (AGT) M235T polymorphism has been associated with salt sensitivity. The aim of the present study was to clarify the association between the AGT M235T polymorphism and gastric cancer. The AGT M235T polymorphism was genotyped using PCR-RFLP analysis in 206 gastric cancers and 210 control biopsies. A logistic-regression analysis was performed to identify an odds ratio to determine whether a correlation exists between genetic polymorphism and risk in patients with gastric cancer as compared to the control samples. Statistical significance was determined using the Mann Whitney $U$ and Chi-square tests. The genotype distribution was found to be $\mathrm{MM}=9$ (4.4\%), $\mathrm{MT}=57(27.7 \%)$, and $\mathrm{TT}=140(67.9 \%)$ in samples from patients with gastric cancer and $\mathrm{MM}=8(3.8 \%), \mathrm{MT}=60(28.6 \%)$ and $\mathrm{TT}=142$ $(67.6 \%)$ in the control samples. The odds ratio of gastric cancer of the MM genotype associated with the $\mathrm{T}$ carrier was $1.0(0.4-2.7)(\mathrm{P}=0.95)$. The distribution pattern of AGT M235T polymorphism in the gastric cancer cases and controls was not found to be significantly different in this study. Thus, it can be concluded that other sites of AGT polymorphism or other salt sensitivity genes may be associated with gastric cancer.
\end{abstract}

\section{Introduction}

Helicobacter pylori (H. pylori) was initially identified in 1986. Since then, this infection has been accepted as a crucial factor in the development of peptic ulcer disease and atrophic gastritis. In addition, it is involved in the development

Correspondence to: Dr Tomoyuki Shibata, Department of Gastroenterology, Fujita Health University School of Medicine, 1-98 Dengakugakubo, Kutsukake-cho, Toyoake, Aichi 470-1192, Japan

E-mail: shibat03@fujita-hu.ac.jp

Key words: gastric cancer, salt sensitivity, angiotensinogen, polymorphism of gastric carcinoma (1-5). However, there are distinct differences in the extent of gastric mucosal inflammation and atrophy among $H$. pylori-infected patients, and only a small group of infected patients develop peptic ulcer disease and gastric cancer. Thus, as yet unknown factors, such as genetic variation, may play significant roles in the long-term outcome of H. pylori infection (6).

Previous studies reported that a high-salt diet is a risk factor for gastric cancers other than those caused by $H$. pylori infection (7-9). Findings of an animal study also revealed that salt did not have an initiation effect for carcinogenesis but rather promoted carcinogenesis (10). The evidence revealed that high salt intake is a risk factor for gastric cancer. However, the mechanism remains to be determined. Certain studies have indicated that the product that results from the mixing of excess sodium chloride and amino acids in the stomach, such as nitrosoamine, may play a role in carcinogenesis (11).

Angiotensinogen (AGT) is one of the most significant elements of the renin-angiotensin system (RAS). AGT and RAS are involved in vascular tone, cardiovascular remodeling, and salt and water homeostasis (12). Marked interest in the AGT M235T polymorphism and its association with hypertension and salt sensitivity has been noted $(13,14)$. This polymorphism was previously reported to be associated with plasma AGT levels (13).

The aim of the present study was to clarify the association of AGT M235T polymorphism in a salt sensitivity gene with gastric cancer risk in a Japanese cohort.

\section{Materials and methods}

Study population. This case-control study was performed with enrolled patients who underwent upper gastrointestinal endoscopy at Fujita Health University Hospital. We studied 416 Japanese patients, who were divided into two groups for assessment of AGT polymorphism. The first group comprised 206 gastric cancer (GC) patients with a mean age of 65.3 years and a male:female (M:F) ratio of 147:59. The second group included 210 patients with no evidence of GC (mean age of 62.8 years and M:F ratio of 128:82) and served as the control group. GC was diagnosed histologically by hospital pathologists and was classified according to Lauren's classification (15). Detailed information was obtained on the tumor stage and the anatomic location. 
The Ethical Committee of Fujita Health University School of Medicine approved the study protocol, and written informed consent was obtained from each patient.

Detection of H. pylori. H. pylori infection status was determined by histology, urea breath test (UBT), and/or a serum titer of antibodies against $H$. pylori. An $H$. pylori infection was diagnosed if at least one of the test results was positive.

DNA extraction. Biopsy specimens were obtained during endoscopy from non-cancerous mucosa on the greater curvature of the antrum. Samples were immediately frozen and maintained at $-80^{\circ} \mathrm{C}$. Genomic DNA was later extracted from these samples by digestion with proteinase $\mathrm{K}$ and phenol (16).

Genotyping of AGT gene polymorphism. The polymorphism of AGT M235T was characterized by a PshAI digestion site. The AGT M235T polymorphism was investigated using PCR-based restriction fragment length polymor-
Table I. Patient characteristics.

No.

$\begin{array}{ccccc}\text { GC group } & & \text { Control group } & & \text { P-value } \\ 206 & & 210 & & \\ 147 / 59 & & 128 / 82 & & \text { N.S. }{ }^{\text {a }} \\ 65.3 \pm 10.7 & & 62.8 \pm 12.7 & & \text { N.S. } \\ 93.2 & & 67.6 & & <0.05^{\text {a }}\end{array}$

GC, gastric cancer; HP, Helicobacter pylori. ${ }^{\mathrm{a}} \mathrm{GC}$ vs. control group, Chi-square test. ${ }^{\mathrm{b}} \mathrm{GC}$ vs. control group, Mann-Whitney U test.

phism (PCR-RFLP) analysis. PCR amplification was performed using the following primers for AGT M235T: 5'-CCGTTTGTGCAGGGCCTGGCTCTCT-3' and 5'-GCCAG GGTGCTGTCCACACTGACTCCC-3'. PCR was performed in a reaction volume of $20 \mu \mathrm{l}$ with $0.1 \mu \mathrm{g}$ of genomic DNA.

Table II. AGT polymorphism and GC risk.

\begin{tabular}{|c|c|c|c|c|}
\hline Genotypes & $\begin{array}{c}\text { GC group } \\
\text { no. }(\%)\end{array}$ & $\begin{array}{c}\text { Control group } \\
\text { no. }(\%)\end{array}$ & $\begin{array}{c}\text { OR }(95 \% \mathrm{CI}) \\
\text { vs. MM }\end{array}$ & P-value \\
\hline MM & $9(4.4)$ & $8(3.8)$ & Reference & \\
\hline MT & $57(27.7)$ & $60(28.6)$ & $1.02(0.34-3.04)$ & 0.975 \\
\hline TT & $140(67.9)$ & $142(67.6)$ & $0.96(0.35-2.64)$ & 0.932 \\
\hline $\mathrm{T}$ carrier & 197 (95.6) & $202(96.2)$ & $0.97(0.35-2.67)$ & 0.952 \\
\hline
\end{tabular}

$\mathrm{GC}$, gastric cancer; CI, confidence interval.

Table III. Association between AGT polymorphism and tumor location, staging and Lauren's classification.

\begin{tabular}{|c|c|c|c|c|c|}
\hline \multirow[t]{2}{*}{ Variables (no.) } & \multicolumn{3}{|c|}{ Genotype } & \multicolumn{2}{|c|}{ TT vs. MM } \\
\hline & MM & MT & TT & OR $(95 \% \mathrm{CI})$ & P-value \\
\hline Patients without GC (210) & 8 & 60 & 142 & Reference & \\
\hline \multicolumn{6}{|l|}{ Tumor location } \\
\hline Cardia (6) & 0 & 2 & 4 & ND & \\
\hline Non-cardia (200) & 9 & 55 & 136 & $1.07(0.39-2.95)$ & 0.901 \\
\hline Upper third (20) & 1 & 4 & 15 & $1.05(0.12-9.39)$ & 0.968 \\
\hline Middle third (102) & 4 & 35 & 63 & $0.93(0.26-3.34)$ & 0.914 \\
\hline Lower third (78) & 4 & 16 & 58 & $1.11(0.31-4.00)$ & 0.876 \\
\hline \multicolumn{6}{|l|}{ Staging } \\
\hline Early (114) & 4 & 30 & 80 & $0.77(0.22-2.71)$ & 0.683 \\
\hline Advanced (92) & 5 & 27 & 60 & $1.39(0.42-4.65)$ & 0.592 \\
\hline \multicolumn{6}{|l|}{ Lauren's classification } \\
\hline Intestinal type (117) & 5 & 30 & 82 & $1.02(0.31-3.37)$ & 0.975 \\
\hline Diffuse type (83) & 4 & 24 & 55 & $1.05(0.29-3.73)$ & 0.944 \\
\hline Mixed (6) & 0 & 3 & 3 & ND & \\
\hline
\end{tabular}

All data are adjusted for gender, age, and H.pylori infection status. GC, gastric cancer; ND, not determined. 
An initial denaturing step at $94^{\circ} \mathrm{C}$ for 5 min was followed by 35 cycles of $94^{\circ} \mathrm{C}$ for $20 \mathrm{sec}, 53^{\circ} \mathrm{C}$ for $20 \mathrm{sec}$, and $72^{\circ} \mathrm{C}$ for $40 \mathrm{sec}$ with a final extension step at $72^{\circ} \mathrm{C}$ for $7 \mathrm{~min}$. The reaction was carried out using the Ex Taq enzyme (Takara Bio Inc., Shiga, Japan). The amplified PCR products were digested overnight at $37^{\circ} \mathrm{C}$ with 5 units of PshAI, and the digested products were subjected to electrophoresis on $3 \%$ agarose gel. The gels were stained with ethidium bromide $(0.5 \mu \mathrm{g} / \mathrm{ml})$. The genotypes and alleles were determined by analysis of the bands as previously described (17).

Statistical analysis. Data were analyzed to assess statistical significance using the Mann-Whitney U and Chi-square tests. Logistic regression analysis was performed to calculate the odds ratios (OR) (18) and 95\% confidence intervals (CI) for AGT polymorphism by comparing the GC and control groups with an adjustment for $H$. pylori infection status. $\mathrm{P}<0.05$ was considered to be statistically significant.

\section{Results}

Study population. A total of 206 GC patients and 210 control subjects without evidence of GC participated in this study. Their characteristics are shown in Table I. No significant differences were observed between the two groups with regards to age or gender distributions, indicating that the observed effects were not due to these two variables. The H.pylori infection rate was found to be higher in the GC patients $(\mathrm{p}<0.05)$.

Distribution of AGT genotypes. Table II shows AGT M235T genotype frequencies in the GC and control groups. The AGT M235T polymorphism was genotyped in all 416 subjects. In the 206 GC patients, the genotype distribution was found to be $\mathrm{MM}=9(4.4 \%), \mathrm{MT}=57(27.7 \%)$ and $\mathrm{TT}=140(67.9 \%)$. In the control patients, the genotype distribution was $\mathrm{MM}=8(3.8 \%)$, MT=60 (28.6\%) and TT=142 (67.6\%). The genotype distribution was not significantly different between the GC and control patients (Table II).

To perform a more detailed investigation, the associations between AGT polymorphism and various clinicopathological characateristics of GC (tumor location, stage and Lauren's histological classification) were assessed by stratified analysis. No significant differences were observed between GC cases and the controls (Table III).

\section{Discussion}

A large number of epidemiologic studies have reported a correlation between a high level of dietary salt intake and an increased risk of gastric cancer (19-21). Findings of studies using animal models have shown that the presence of $H$.pylori and a high-salt diet have a synergistic effect on gastric carcinogenesis $(10,22)$. These associations have been detected in both prospective and case-control studies $(8,23,24)$. These studies reported that $H$. pylori-infected subjects who consumed a high-salt diet had an increased risk of gastric cancer when compared to $H$. pylori-infected subjects who consumed lower levels of salt. The mechanism by which a high-salt diet increases the risk of gastric cancer in humans has yet to be clarified. One possibility is that salt may have direct effects on the gastric mucosa that lower the threshold for malignant transformation (25). Another proposed explanation is that salt damages the gastric mucosa, thereby allowing increased entry of carcinogens into gastric tissue (26).

Cardiac investigators are engaged in finding a genetic association between salt sensitivity and hypertension. AGT is a salt sensitivity gene involved in this process and is a significant gene in the RAS system. As previously mentioned, the AGT M235T polymorphism was reported to be associated with the plasma AGT levels (13). The T235 allele varies widely in frequency, occurring in $35-45 \%$ of subjects of Caucasian descent, $75-80 \%$ of Asians and African Americans, and $90 \%$ of subjects of African descent $(27,28)$. These distribution differences led to a hypothesis that the T235 allele, which is associated with a higher AGT expression and greater sodium reabsorption, was adaptive in the tropical, sodium-poor environment of subSaharan Africa. However, this hypothesis was rejected due to demographic relocation by these population groups.

The T235 polymorphisms may predispose populations to hypertension and other disorders when resources are prevalent and overconsumed (29). It was proposed that this polymorphism leads to a susceptibility to gastric mucosal damage in the presence of high concentrations of salt due to AGT concentration levels. For these reasons, we focused on the M235T polymorphism of a salt sensitivity gene, AGT. This is the first investigation into a possible correlation between a salt sensitivity gene and gastric carcinogenesis. Previously, the relationship between genes in the renin-angiotensin system and the risk of gastric cancer was investigated (30-34). One study reported a correlation between the A-20C AGT polymorphism and an increased risk of gastric cancer (34). However, results of our study revealed no association between the AGT M235T polymorphism and gastric cancer risk. One reason for this inconsistency is the different linkage disequilibrium between M235T and other polymorphism sites in the gene. The AGT M235T polymorphism exhibits a strong linkage disequilibrium with the AGT G-6A and T68C polymorphisms, but only a weak linkage disequilibrium with the AGT A-20C polymorphism (35). Further studies are required to investigate other sites of AGT gene polymorphisms and gastric cancer susceptibility to confirm this theory.

In conclusion, the distribution pattern of the AGT M235T polymorphism in cases of GC and controls was not found to be significantly different in this study. No association was found between the AGT M235T polymorphism and patient susceptibility to gastric cancer. Therefore, other polymorphism sites in the AGT gene or other genes related to salt sensitivity may be associated with gastric cancer development.

\section{Acknowledgements}

We thank all of the medical staff at the endoscopy unit at Fujita Health University Hospital for obtaining samples, and Ms. Y. Kimura for her scientific input.

\section{References}

1. Yamada T: NIH consensus conference. Helicobacter pylori in peptic ulcer disease. NIH consensus development panel on Helicobacter pylori in peptic ulcer disease. Journal 272: 65-69, 1994. 
2. Uemura N, Okamoto S, Yamamoto S, et al: Helicobacter pylori infection and the development of gastric cancer. $\mathrm{N}$ Engl $\mathrm{J}$ Med 345: 784-789, 2001.

3. Parsonnet J, Friedman GD, Vandersteen DP, et al: Helicobacter pylori infection and the risk of gastric carcinoma. N Engl J Med 325: 1127-1131, 1991.

4. Huang JQ, Sridhar S, Chen Y and Hunt RH: Meta-analysis of the relationship between Helicobacter pylori seropositivity and gastric cancer. Gastroenterology 114: 1169-1179, 1998

5. Blaser MJ and Parsonnet J: Parasitism by the 'slow' bacterium Helicobacter pylori leads to altered gastric homeostasis and neoplasia. J Clin Invest 94: 4-8, 1994.

6. Amieva MR and El-Omar EM: Host-bacterial interactions in Helicobacter pylori infection. Gastroenterology 134: 306-323, 2008.

7. Tsugane S: Salt, salted food intake, and risk of gastric cancer: epidemiologic evidence. Cancer Sci 96: 1-6, 2005.

8. Shikata K, Kiyohara Y, Kubo M, et al: A prospective study of dietary salt intake and gastric cancer incidence in a defined Japanese population: the Hisayama study. Int J Cancer 119: 196-201, 2006

9. Weisburger JH: Dietary risk factors for gastric carcinoma Journal of the American Association 291: 1564, 2004

10. Nozaki K, Shimizu N, Inada K, et al: Synergistic promoting effects of Helicobacter pylori infection and high-salt diet on gastric carcinogenesis in Mongolian gerbils. Jpn J Cancer Res 93: 1083-1089, 2002.

11. Correa P, Haenszel W, Cuello C, Tannenbaum S and Archer M: A model for gastric cancer epidemiology. Lancet 306: 58-60, 1975.

12. MacGregor GA, Markandu ND, Roulston JE, Jones JC and Morton JJ: Maintenance of blood pressure by the renin-angiotensin system in normal man. Nature 291: 329-331, 1981.

13. Jeunemaitre X, Soubrier F, Kotelevtsev YV, et al: Molecular basis of human hypertension: role of angiotensinogen. Cell 71: 169-180, 1992

14. Caulfield M, Lavender P, Farrall M, et al: Linkage of the angiotensinogen gene to essential hypertension. N Engl J Med 330: $1629-1633,1994$

15. Lauren P: The two histological main types of gastric carcinoma: diffuse and so-called intestinal-type carcinoma. An attempt at a histo-clinical classification. Acta Pathol Microbiol Scand 64: 31-49, 1965

16. Sambrook J and Russell DW (eds): Preparation and analysis of Eukaryotic genomic DNA. In: Molecular Cloning A Laboratory Manual. Vol 1. 3rd edition. Cold Spring Harbor Laboratory Press, New York, NY: 2001, pp6.1-6.64.

17. Lizanecz E, Pasztor ET, Mohacsi A, Papp Z, Edes I and Toth A: Mistyping of angiotensinogen M235T alleles. Hypertens Res 29 197-201,2006.

18. Thorstenson A, Jacobsson H, Onelov E, Holst JJ, Hellstrom PM and Kinn AC: Gastrointestinal function and metabolic control after construction of an orthotopic ileal neobladder in bladder cancer. Scand J Urol Nephrol 41: 14-19, 2007.

19. Tsugane S and Sasazuki S: Diet and the risk of gastric cancer: review of epidemiological evidence. Gastric Cancer 10: 75-83, 2007.
20. Correa P: Human gastric carcinogenesis: a multistep and multifactorial process-first American Cancer Society award lecture on cancer epidemiology and prevention. Cancer Res 52: 6735-6740, 1992.

21. Fuchs CS and Mayer RJ: Gastric carcinoma. N Engl J Med 333 32-41, 1995

22. Kato S, Tsukamoto T, Mizoshita T, et al: High salt diets dose-dependently promote gastric chemical carcinogenesis in Helicobacter pylori-infected Mongolian gerbils associated with a shift in mucin production from glandular to surface mucous cells. Int J Cancer 119: 1558-1566, 2006.

23. Kim MK, Sasaki S, Sasazuki S and Tsugane S: Prospective study of three major dietary patterns and risk of gastric cancer in Japan. Int J Cancer 110: 435-442, 2004.

24. Lee SA, Kang D, Shim KN, Choe JW, Hong WS and Choi H: Effect of diet and Helicobacter pylori infection to the risk of early gastric cancer. J Epidemiol 13: 162-168, 2003.

25. De Koster E, Buset M, Fernandes E and Deltenre M Helicobacter pylori: the link with gastric cancer. Eur J Cancer Prev 3: 247-257, 1994.

26. Furihata $\mathrm{C}$, Ohta $\mathrm{H}$ and Katsuyama $\mathrm{T}$ : Cause and effect between concentration-dependent tissue damage and temporary cell proliferation in rat stomach mucosa by $\mathrm{NaCl}$, a stomach tumor promoter. Carcinogenesis 17: 401-406, 1996.

27. Corvol P, Jeunemaitre X, Charru A, Kotelevtsev Y and Soubrier F: Role of the renin-angiotensin system in blood pressure regulation and in human hypertension: new insights from molecular genetics. Recent Prog Horm Res 50: 287-308, 1995.

28. Staessen JA, Kuznetsova T, Wang JG, Emelianov D, Vlietinck R and Fagard R: M235T angiotensinogen gene polymorphism and cardiovascular renal risk. J Hypertens 17: 9-17, 1999.

29. Nakajima T, Jorde LB, Ishigami T, et al: Nucleotide diversity and haplotype structure of the human angiotensinogen gene in two populations. Am J Hum Genet 70: 108-123, 2002.

30. Ebert MP, Lendeckel U, Westphal S, et al: The angiotensin I-converting enzyme gene insertion/deletion polymorphism is linked to early gastric cancer. Cancer Epidemiol Biomarkers Prev 14: 2987-2989, 2005.

31. Goto Y, Ando T, Nishio K, et al: The ACE gene polymorphism is associated with the incidence of gastric cancer among $H$. pylori seropositive subjects with atrophic gastritis. Asian Pac J Cancer Prev 6: 464-467, 2005.

32. Rocken C, Lendeckel U, Dierkes J, et al: The number of lymph node metastases in gastric cancer correlates with the angiotensin I-converting enzyme gene insertion/deletion polymorphism. Clin Cancer Res 11: 2526-2530, 2005.

33. Sugimoto M, Furuta T, Shirai N, Ikuma M, Sugimura H and Hishida A: Influences of chymase and angiotensin I-converting enzyme gene polymorphisms on gastric cancer risks in Japan. Cancer Epidemiol Biomarkers Prev 15: 1929-1934, 2006.

34. Sugimoto M, Furuta T, Shirai N, et al: Role of angiotensinogen gene polymorphism on Helicobacter pylori infection-related gastric cancer risk in Japanese. Carcinogenesis 28: 2036-2040, 2007.

35. Ishigami T, Tamura K, Fujita T, et al: Angiotensinogen gene polymorphism near transcription start site and blood pressure: role of a T-to-C transition at intron I. Hypertension 34: 430-434, 1999. 